the man as a lover and to instruct in the whole business of initiation into the man's world. Homosexuality, according to Layard, is intimately bound up with the operation of incision or circumcision, and it seems pretty clear that the importance of homosexuality in patrilinear groups is due to the fact that the inspiration of the ancestral spirits is imparted to the novice through the ritual homosexual act. The operation of incision is an act of sacrifice which invariably precedes the initiation into manhood. Since, therefore, the world of the spirits is, essentially, the spiritual world, we can assume that there are certain phases in the evolution of mankind in which the organization and cultivation of the masculine, spiritual principle needs to predominate over the more material and earthly feminine principle. It was, for example, during the formation and building up of the Greek city-states, when the mas. culine martial qualities were especially needed, that homosexuality was similarly legalized. In this connexion it is instructive to read that man acquires a soul only through sacrifice. Therefore, women and boys have neither souls nor ghosts. The critical importance given to this idea of sacrifice, first in the operation of incision and, later, in the elaborate cultivation of the tusked boars for sacrifice, seems to point to the conclusion that already the idea of gaining spiritual power through the sacrifice of some part of the animal nature has begun to operate, albeit in the primitive concretistic way.

These stray comments give, I fear, only a very inadequate rendering of the immense labours which the author has put into the work. It is indeed a monument erected by a devoted worker to that vast primordial realm which will ever remain the very groundwork and basis of the human mind.

H. G. BAYNES.

\section{ELECTRICAL TECHNOLOGY}

Applied Electricity

By A. W. Hirst. Pp. xi +290 . (London and Glasgow : Blackie and Son, Ltd., 1942.) 15s. net.

$\mathrm{T}$ HE mere change of title from 'electrical technology' to 'applied electricity' for the Part I paper in the examination for the University of London degree in engineering means very little to electrical students, who have to study all their subject whatever it is called. That the same course is to be taken by all other engineering students is another matter, and difficulties must arise when the educationist has to decide what amount of his special subject has to be presented to students who are to become civil or mechanical engineers. For the latter, the more subtle aspects of electrical engineering can well be omitted, with more emphasis on the broader issues of economy, types of electric drive, transmission systems, and even protection. The author has used his experience in this matter to present a text-book which covers both this ground and that for the examinations of the Institution of Electrical Engineers-what may be called the step between the electricity of physics and the specialized technology used by the qualified electrical engineer. The selection of material, the examples, emphasis on practical magnitudes, and diagrams are excellent, but one has qualms about non-electrical students taking this course.
There are a large number of footnotes in this first edition, and one wonders why they could not be incorporated in the text, because they are generally highly relevant and give valuable practical hints. There are two criticisms of the author's material which one can make. The first is that electrical engineers are very keen on the difference between electro-motive force and potential difference, and one cannot subscribe to the idea that the terms "ohmic drop" and "resistance drop" are better rendered as "counter E.M.F. of resistance" or "resistance E.M.F." (p. 70). A resistance may have an E.M.F. in it, but the telecommunications engineer would say that it has something to do with the thermal agitation of free electrons. As a consequence, the author deduces from Kirchoff's laws that "the algebraic sum of all the E.M.F.'s in any closed circuit is zero", which, to an engineer, would be highly fortuitous. Again, "the algebraic sum of the E.M.F.'s in the connected circuit is equal and opposite to the supply P.D.", which is exactly opposite to what an engineer would say, because he identifies the magnitudes of the E.M.F. maintaining the P.D. of a supply only when either no current is taken or the supply has no sourceimpedance. The engineer would likewise reverse "the vector sum of all the E.M.F.'s in the connected system is equal and opposite to the supply P.D.".

The second point at issue is the source of the torque which drives the rotor of an electrical machine. The author says (p. 41) "the force on the conductor produces a torque"; again (p. 46), "Torque is proportional to armature current multiplied by flux per pole"; also, (p. 171) Fig. 24, (a) and (b) clearly show forces only on stator conductors, and the text states "the armature rotates under the forces acting on the armature conductors". Now this is physically not so. There is certainly a flux-density at the location of any current-carrying conductor opposite a pole, but this conductor is magnetically short-circuited by the teeth of the magnetic material nearly surrounding such conductor, and consequently the flux-density at the conductor is very low in comparison with the average flux-density over the arc of the opposing pole face. With, current in the conductor, the coexisting flux augments the pole flux in the tooth on one side and diminishes the pole flux on the other. It is due to this asymmetry of flux distribution with respect to each conductor that the teeth exhibit an unbalanced tangential force which is the actual force, when taken for all teeth, making the rotor revolve in a motor, or oppose rotation in a generator. Each conductor is actually cutting a very weak field at a velocity greatly exceeding that of the circumferential speed of the rotor. It is an unjustifiable assumption that the conductors are cutting the average fluxdensity at the circumferential speed, although this assumption fortunately leads to a correct calculation of torque and electro-motive force arising from rotation. There is no controversy here between the alleged rival flux-cutting and flux-linking theories, but merely a discussion regarding the source of the torque in a rotor. If there were no iron in the rotor, the torque would obviously be on the conductors. In Fig. $24(d)$, (p. 171), the author gets to a tangential component of magnetic force but for a different reason, that of maintaining synchronization.

The author has covered a wide field with clarity and conciseness, and his book will certainly be of value to electrical engineering, if no other, students. 